\title{
Künstliches Holz
}

wird in Frankreich dargestellt durch Mengen feiner Sägespäne mit Blut und Druck unter einer hydraulischen Presse, um bestimmte Formen zu erhalten. Die trockne Masse ist sehr hart, schwerer als jedes andere natürliche Holz und lässt sich sehr schön poliren. (Journ. de Pharm. d'Anvers. Novbr. 1863.)

Dr. Reich.

\section{Rosenrothe Färbung des llolzes.}

Um Holz und besonders das regetabilische Elfenbein rosenroth zu färben, bereitet man nach Monnier zwei Bāder: eines von Jodkalium mit $80 \mathrm{Grm}$. Salz im Liter, das andere von Quecksilbersublimat mit $25 \mathrm{Grm}$. Salz im Liter. Das zu färbende Holz wird einige Stunden in das erste Bad gebracht, dann in das zweite, wo es eine schöne Rosenfarbe annimmt. (Journ. de Pharm. d'Anvers. Mai 1863.)

Dr. Reich.

\section{Surrogat der Guttapercha von Kappler in Surinam.}

Viele Bäume in Guyana liefern Milchsiifte; es zeichnet sich unter diesen der Balatas (Achras) aus, der zugleich ein vortreffliches Bauholz liefert. Seit cinigen Jahren lässt das französische Gouvernement durch Sträflinge den Saft sammeln, von welchem täglich eine bestimmte Menge abgeliefert werden muss. Dieser Saft könnte die schwieriger zu erhaltende Guttapercha ersetzen, da der Baum sich häufig findet, doch lässt der noch hohe Preis und andrerseits das Misstrauen des Publicums gegen Neues fürchten, dass man bei den ersten Versuchen stehen bleiben wird. (Journ. de Pharm. d'Anvers. Déc. 1863.)

Dr. Reich.

\section{Im Pelzwerk zu sehützen,}

fügt man zu $100 \mathrm{Th}$. Weingeist etwa $8 \mathrm{Th}$. Campher und 8 zerkleinerte Schoten spanischen Pfeffers. Wenn nach einigen Tagen der Maceration der Campher sich gelöst hat, giesst man durch Leinwand. Man besprengt damit möglichst gleichmässig das Pelzwerk oder die wollenen Kleidungsstücke und rollt sie fest in ein starkes Tuch. - Der spanische Pfeffer kann auch durch Coloquinthen ersetzt werden. (Journ.de Pharm.d'Anvers. JuilletAoat 1863.) Dr. Reich. 